\title{
Tremor mimicking ventricular tachycardia (VT): Treat your patients, not the ECG
}

\author{
Yos A Irmansyah ${ }^{1,3 *}$ and AASG Mas Meiswaryasti Putra ${ }^{2,3}$ \\ ${ }^{1}$ Emergency Department of Mataram Public Hospital, Indonesia \\ ${ }^{2}$ Cardiology Department of Mataram Public Hospital, Indonesia \\ ${ }^{3}$ Medical Faculty of Mataram University, Indonesia
}

\begin{abstract}
Introduction: Artefacts are common finding in the electrocardiogram (ECG) of patients in hospital setting. It can mimic a number of arrhythmias causing patients to be subjected to unnecessary and potentially dangerous therapeutic interventions. ECG's artefacts can be generated by internal and external cause from muscle tremors to dry electrode gel. A thorough knowledge of, patient's history, hemodynamic profile, and appropriate investigation of surrounding equipment/monitors enables swift determination of the cause and appropriate action for resolving the problem.

Case Report: A-44-year old male was referred to emergency department (ED) with chest pain. He denied any shortness of breath, dyspnoea, orthopnoea, palpitations, or syncope. He had a history of hypertension for about 1 year without routine anti hypertension therapy. Physical exam was remarkable for unilateral hand resting tremors at left side with frequency of 6-8 hertz and mild cogwheel rigidity in left hand. His vital sign were normal with BP $140 / 80$ mmHg, pulse 72 bpm regular, RR 20 times per minute, Sp02 100\% room air. His initial labs were within normal limits. The 12-leads-ECG showed wide QRS complex tachycardia in limb leads (I, II, III, AvL, AvR, AvF) as in Ventricular Tachycardia (VT).
\end{abstract}

Conclusion: The key to diagnose a patient whether it is true arrhythmia or not, must always involve symptoms and physical examination findings, rather than based on ECG alone.

\section{Introduction}

An electrocardiogram (ECG) is one of an important bedside investigation technique used for finding abnormalities and to help diagnose cardiac diseases [1]. Fine skills are needed to match the symptoms of the patient with their ECG findings to make a diagnosis in heart disease, because artefacts are also common findings in an ECG at in-patient setting which sometimes can lead to misreading as tachyarrhythmias [2].

As a clinician, we should be aware and consider whether this is as an artefact or true tachyarrhythmia, especially in asymptomatic patient with stable hemodynamic. In this case report, we present an interesting case in the diagnosis of mimicking Ventricular Tachycardia due to resting tremor.

\section{Case Presentation}

A-44-year old male was referred to emergency department (ED) with chest pain. He denied any shortness of breath, dyspnoea, orthopnoea, palpitations, or syncope. He had a history of hypertension for about 1 year without routine anti hypertension therapy. Physical exam was remarkable for unilateral hand resting tremors at left side with frequency of 6-8 hertz and mild cogwheel rigidity in left hand. His vital sign were normal with BP $140 / 80 \mathrm{mmHg}$, pulse $72 \mathrm{bpm}$ regular, RR 20 times per minute, Sp02 100\% room air. His initial labs were within normal limits with 2 negative troponins $(0.8 \mathrm{~nL}$ and 0.6 $\mathrm{nL}$ ). The amount of sodium, potassium, chloride, carbon dioxide, and creatinine are normal. We performed a 12-lead ECG, and showed wide QRS complex tachycardia in limb leads (I, II, III, AvL, AvR, AvF) as in Ventricular Tachycardia. (Figure 1).

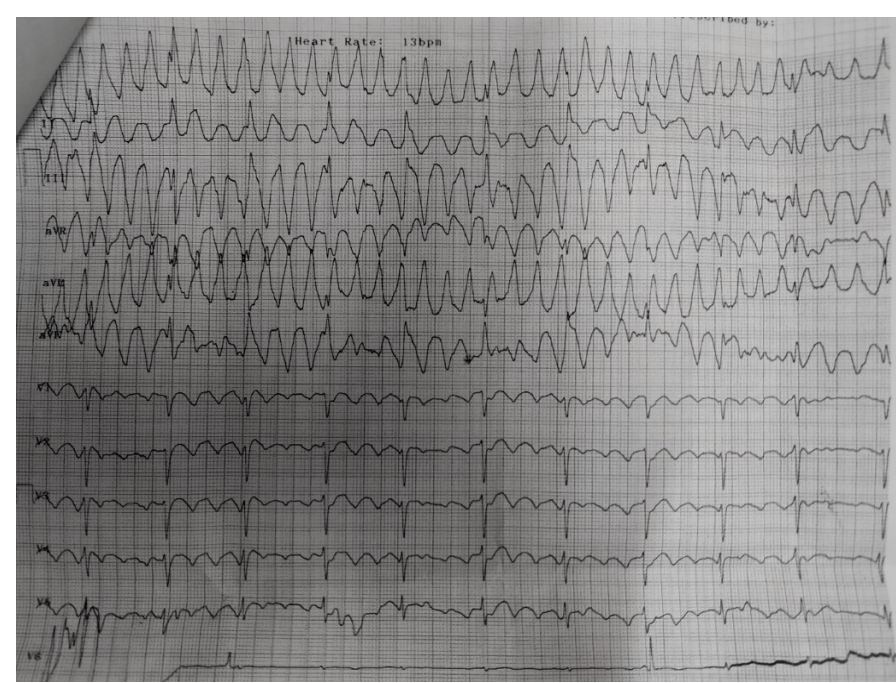

Figure 1. The 12-leads ECG patient at glance in ED initially interpret as ventricular tachycardia

*Correspondence to: Yos Akbar Irmansyah, General practitioner in Emergency Department of Mataram Public Hospital, Lombok, Indonesia, E-mail: yosakbar92.dr@gmail.com

Key words: electrocardiography; artefacts; tremor; ventricular arrythmias; ventricular tachycardia

Received: August 31, 2020; Accepted: September 10, 2020; Published: September 15,2020 


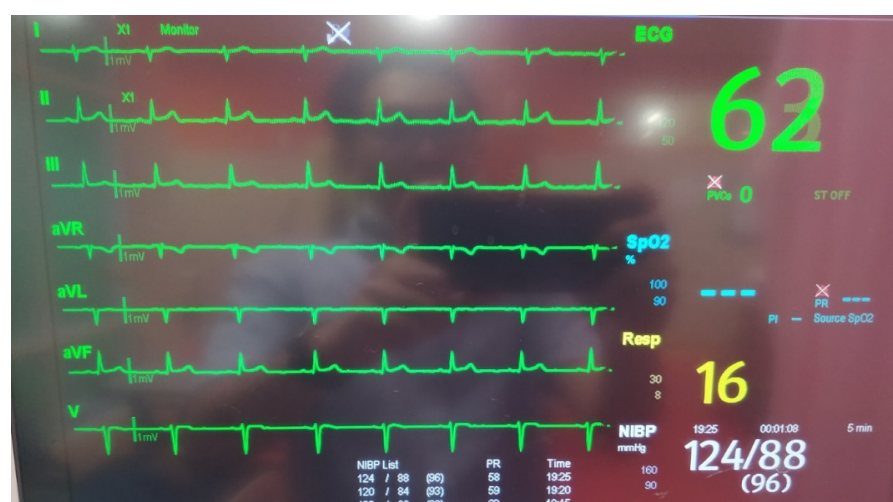

Figure 2. Chest lead that presence in screen monitor showed normal ECG

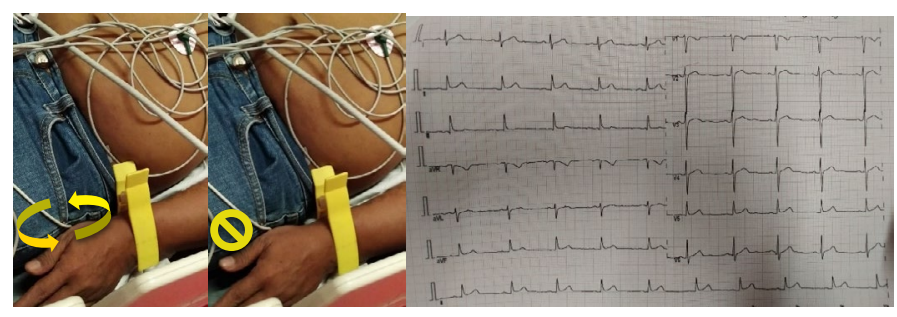

Figure 3. (Left) showed the movement of left hand in resting tremor make circular pattern, while the movement was minimized by holding the hand, it showed a normal wave in 12-leads ECG (Right)

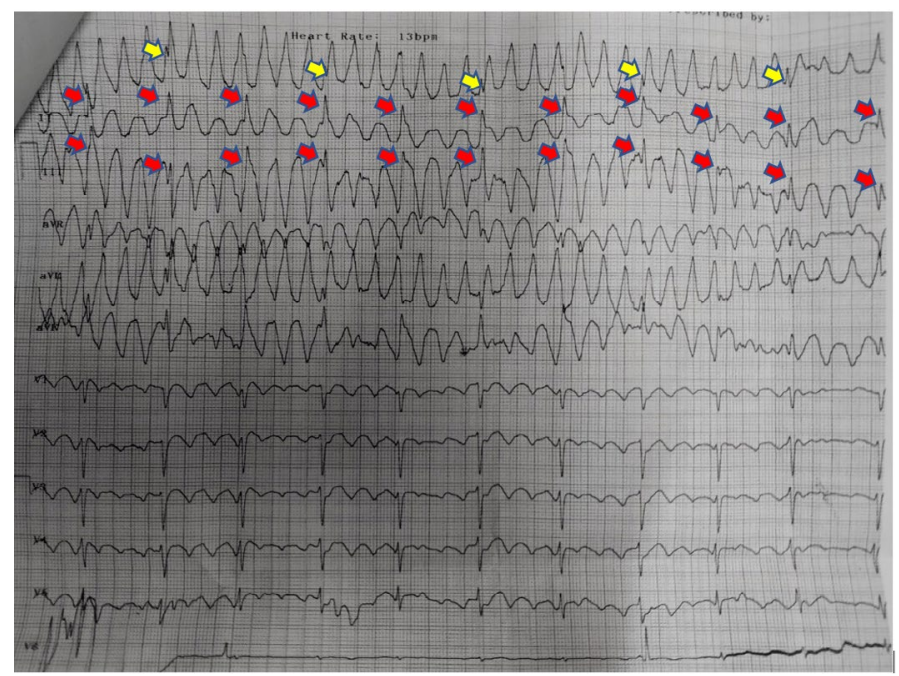

Figure 4. The red arrow shows an "R" waves with spike and the yellow arrow shows the notch sign. This sign means normal ventricular response and always finds in "pseudo"-VT that describe as artefacts waves

The 12-lead ECG showed different wave with the monitor that was also placed on the patient. The monitor showed no abnormal waves present (Figure 2). We were doubting the result of the 12-lead ECG and started to re-examine the patient to determine what went wrong, whether there was a problem with the machine or any other contributing factors.

After researching and re-evaluating the patient, we think the tremors in his left hand (Figure 3) was causing the wave that presented in the ECG. We tried to hold the left hand to prevent the tremor and conducted another 12-lead ECG examination. After completely minimizing the tremor, the 12-lead ECG showed normal wave (Figure 3).
Several records are made to confirm the hypothesis, whether it is a true VT or just an artefact caused by tremor that was mimicking VT, and after holding the hand to minimize the tremor, the 12-lead ECG showed normal results, but the VT-like wave is still present if we conduct the ECG without minimizing the tremor. No abnormalities were found in cardiac markers, electrolytes, routine laboratory testing, and his echocardiography.

\section{Discussion}

Artefact is a common finding in the ECG of patients in hospital setting. Artefacts are defined as ECG abnormalities that may be due to sources other than the electrical activity of the heart. It can mimic several arrhythmias causing patients to be subjected to unnecessary and potentially dangerous therapeutic interventions. One of the most leading to misinterpret was tremor that is caused by muscular activity. ${ }^{1}$ Other causes of ECG artefacts is showed in (Table 1) [3].

Tremor induced artefact can be misinterpreted as ventricular arrhythmias if the amplitude is sufficient [6]. Several clinical symptoms and electrographic characteristics to differentiate tremor induced artefacts from true cardiac arrhythmias should be routinely observed, because it can occur not only in cardiac disease but also in many noncardiac conditions that can mimic cardiac pathology such as in (Table 1). When obtaining an ECG, it is necessary to minimize environmental interference, such as patient movement, speaking, electromagnetic interference such as cell phones, and to limit the activity of muscle such as tremor if possible [7].

Table 1. Most frequent causes of ECG artefact

Internal (Physiological)

- Muscular activity: allows electronic filtration (small spikes)

- Patient motion: does not allow electronic filtration (large swings, usually by stretching the epidermis)

\section{External (Non-Physiological)}

- Electromagnetic interference: (wide isoelectric line)

a. Light fixtures

b. Electrocautery

c. Electrical devices in the room

- Cable and electrode malfunction

a. Insufficient amount of electrode gel

b.Fractured wires

c. Inappropriate filter settings

d.Loose connections

e. Misplaced leads

f. Accumulation of static energy

Table 2. Several cases that showed an artefact can mimicking arrythmias

\begin{tabular}{|l|l|l|l|}
\hline Case Author & Case Description & Artefact Source & Result \\
\hline $\begin{array}{l}\text { Matthias A T, } \\
\text { Indrakumar J. 2014 } \\
\text { [1]. }\end{array}$ & $\begin{array}{l}\text { A-80-year-old man, } \\
\text { ECG describe as } \\
\text { Atrial Fibrillation. }\end{array}$ & $\begin{array}{l}\text { Shivering due to post } \\
\text { operatic period in } \\
\text { carotid massage, and } \\
\text { adenosine but no } \\
\text { hyange in ECG. }\end{array}$ \\
\hline $\begin{array}{l}\text { Sareen S, et al. 2018 } \\
\text { [2]. }\end{array}$ & $\begin{array}{l}\text { A-72-year old } \\
\text { female, ECG } \\
\text { describe as Atrial } \\
\text { Flutter. }\end{array}$ & $\begin{array}{l}\text { Normal ECG was } \\
\text { recorded after } \\
\text { shivering's gone. }\end{array}$ \\
\hline $\begin{array}{l}\text { Mirijello A, Fuorlo } \\
\text { M, extremity al. 2014 [4]. } \\
\text { Parkinson disease. }\end{array}$ & $\begin{array}{l}\text { A-70-year-old } \\
\text { woman, ECG } \\
\text { describe as VT with } \\
\text { aspect of Torsades de } \\
\text { Pointes (TdP) }\end{array}$ & $\begin{array}{l}\text { Right upper } \\
\text { extremity tremor. } \\
\text { needed. } \\
\text { Normal ECG }\end{array}$ & $\begin{array}{l}\text { Nontion } \\
\text { needed } \\
\text { Normal ECG }\end{array}$ \\
\hline $\begin{array}{l}\text { Pieter M, Peter S. } \\
\text { 2015 [5]. }\end{array}$ & $\begin{array}{l}\text { A-92-year-old } \\
\text { woman, ECG } \\
\text { describe as VT. }\end{array}$ & $\begin{array}{l}\text { Left hand tremor, } \\
\text { cause by the anxious. }\end{array}$ & $\begin{array}{l}\text { No intervention } \\
\text { needed } \\
\text { Normal ECG }\end{array}$ \\
\hline
\end{tabular}


We've been searching for studies about how many an artefact such as muscle tremors can mimic ventricular arrhythmias in the last 5-10 years, but there were not many studies which reported them. Many of the studies that we searched has Parkinson as their underlying disease.

As we know in the basic ECG there are three most commonly employed lead positions used today are referred to leads I, II, and III as an equilateral triangle which is known as Einthoven's triangle. Those leads are the bipolar limb leads that has been used this far in 12-lead ECG. There are three other leads that use the limb electrodes; these are referred to as the augmented unipolar limb leads. The voltage that is recorded between the left arm and the neutral reference lead is called lead aVL; also, between the right arm is aVR, and the left leg lead is aVF. In every case that we found also in our case, the abnormal waves present in the 12-lead ECG most commonly happens in leads I, II, III, aVR, aVL and aVF (Figure 1). That explains why the artefact cause by muscle tremors are prominent in limb leads and represents the action potentials of striated muscle $[8,9]$. We can minimize the tremor that happens in limb leads, like holding the hand, or other tremor extremity to minimize this artefact (Figure 3), or we can place an electrode on the chest that is far from disturbances (Figure 2).

We have to be very careful to diagnose whether it is an artefact or true arrhythmia. There are several ways to confirm the ECG. First, try to figure or "track" the R-R intervals. The R-R intervals always presented as normal ventricular depolarizations throughout the "pseudo"ventricular tachycardia [3]. This method is very helpful if they can be identified before the ventricular tachycardia wave.

There are 3 signs to determine whether its true VT or "pseudo"VT: (1) Sinus sign: one of the frontal leads (I, II, or III) shows normal P waves, QRS complexes, and T waves because usually one of the upper limbs is free of tremor or movement; (2) Spike sign: tiny spikes can be seen among wide QRS like complexes; (3) Notch sign: notches are superimposed in the wide QRS-like complex artefact that "time out" with preceding R-R intervals [10]. In (Figure 4), we can track the " $R$ " wave (red arrow) which is clearly seen in lead II and III (frontal leads) and the "R-R" intervals are regular, also there are tiny spikes sign in "R" wave and notch. The chest leads (V1-V6) also showed very clear " $R$ " wave, we can conclude this ECG has no VT wave, but only the artefact caused by tremors. Besides that, this patient has stable hemodynamic that does not match with true VT symptoms.

\section{Conclusions}

In conclusion, our case report aims to emphasize that the key to diagnose a patient whether it is true arrhythmia or not must always involve symptoms and physical examination findings rather than based on ECG alone, because as physicians we're not treating the ECG but the patien

\section{References}

1. Matthias AT, Indrakumar J (2014) Electrocardiogram artifact caused by rigors mimicking narrow complex tachycardia: a case report. BMC Res Notes 7: 1-3. [Crossref]

2. Sareen S, Nayyar M, Wheeler B, Skelton M, Khouzam RN (2018) Electrocardiographic artifact potentially misleading to the wrong management. Ann Transl Med 6: 17. [Crossref]

3. Baranchuk A, Shaw C, Alanazi H, Campbell D, Bally K, et al. (2009) Electrocardiography pitfalls and artifacts: the 10 commandments. Crit Care Nurse 29: 67-73. [Crossref]

4. Mirijello A, Fuorlo M, Addolorato G, Landolfi R (2014) Doctor, treat your patient, not your monitor!' Tremor-induced ECG artefacts mimicking torsades de pointes. BMJ Case Rep 1-2. [Crossref]

5. Martens $\mathrm{P}$, Sinnaeve $\mathrm{P}$ (2015) Tremor mimicking ventricular tachycardia. CMAJ 187 : 1-2. [Crossref]

6. Patel S (2006) Electrocardiographic artifact mimicking ventricular tachycardia during high-frequency oscillatory ventilation: a case report. Am J Crit Care 15: 310-311. [Crossref]

7. Van Mieghem C, Sabbe M, Knockaert D (2004) The clinical value of the ECG in noncardiac conditions. Chest 125: 1561-1576. [Crossref]

8. Dupre A, Vincent S, Iaizzo (2005) Basic ECG Theory, Recordings, and Interpretations. Handbook of Cardiac Anatomy, Physiology, and Devices Human Press: Totowa, NJ. 191-193.

9. Robottom BJ, Weiner WJ (2010) Teaching Neuro Images: rest tremor mimicking ventricular tachycardia. Neurology 75: 2134. [Crossref]

10. Huang CY, Shan DE, Lai CH, Fong MC, Huang PS, et al. (2006) An accurate electrocardiographic algorithm for differentiation of tremor-induced pseudoventricular tachycardia and true ventricular tachycardia. Int J Cardiol 111: 163-165. [Crossref]

Copyright: $\bigcirc 2020$ Irmansyah YA. This is an open-access article distributed under the terms of the Creative Commons Attribution License, which permits unrestricted use, distribution, and reproduction in any medium, provided the original author and source are credited. 